\title{
Slime Production Among Uropathogenic Bacterial Isolates: Evaluating Different Phenotypic Detection Methods
}

\author{
Pallavi Sayal ${ }^{1 *}$, Raminder Sandhu ${ }^{1}$, Kanwardeep Singh ${ }^{2}$ and Pushpa Devi ${ }^{2}$ \\ ${ }^{1}$ Department of Microbiology, BPS,GMC (W), Khanpur Kalan, Sonepat, Haryana, India \\ ${ }^{2}$ Department of Microbiology, GMC, Amritsar, Punjab, India
}

\begin{abstract}
Background: Biofilms are surface associated bacterial communities surrounded by a matrix of Exo -polymers. Biofilms contribute to the development of chronic urinary infections, refractory to antibiotic therapy.

Methods: This prospective study was done on 150 non-repetitive urine samples from catheterized patients. Semi-quantitative bacterial culture was performed and isolates were identified by standard biochemical tests. Biofilm formation was detected by Congo Red Agar Method (CRA), Tube Method (TM) and Tissue Culture Plate Method (TCP).

Result: Significant bacteriuria was observed among 113/150(74.66\%) samples. Gram negative bacteria (GNB) were predominant isolates $101(89.38 \%)$ and among GNB, Escherichia coli was commonly isolated 30/101(29.70\%).Non E.coli Enterobacteriaceae (NECE) isolates include Klebsiella spp. 25/101(24.75\%), Citrobacter spp 07/101(6.93\%), Proteus spp. 17/101(16.83\%) among non-fermenter bacteria Pseudomonas aeruginosa 21/101(20.79\%). Gram positive bacteria (GPB) constitute 12/113(10.61\%) among total isolates. Biofilm producers detected by TCP were 79(69.91\%), TM 60(53.09\%) and CRA 11(9.73\%) respectively.
\end{abstract}

Conclusion: Detection of biofilms can be recommended for recurrent and recalcitrant infections before institution of empirical antibiotics. TCP method with good reproducibility and specificity which can be used for detection of biofilms in resource limited settings.

\section{Keywords: Bacterial Biofilm, Uropathogens, TCP, Urinary Catheters}

\section{Introduction}

First described by Leeuwenhoek, as sessile bacterial communities characterized by irreversible adherence to each other or substratum embedded in matrix of extra cellular polysaccharides (EPS), called biofilm. ${ }^{[1]}$ With the advancement in medicine and increased use of life saving prosthetic devices, microbial biofilm has emerged as significant clinical problem in treatment and management of infectious diseases. ${ }^{[2]}$ Researchers have estimated 60-80 percent of microbial infections in body are caused by bacteria growing as a biofilm, opposed to planktonic bacteria. ${ }^{[3]}$

Over past few decades much has been learned about biofilm physiology. Biofilms display unique properties of multidrug tolerance and resistance to both opsonization and phagocytosis, enabling them to survive in hostile environmental conditions and to resist selective pressures. Because of inert nature of bacterial biofilms, host immunity is totally ineffective at clearing them. Biofilms in vivo are very difficult to diagnose essentially due to the lack of sampling methods and markers. ${ }^{4}$

Thus, this present study is designed to shed light on current understanding about biofilm phenomenon, its impact on indwelling urinary catheter associated infection and to compare in vitro qualitative and quantitative detection techniques in an attempt to choose sensitive and easy to perform screening method.

\section{Materials and Methods}

Study Design: This prospective study was undertaken in the Department of Microbiology in a tertiary care hospital. A total of 150 non-repetitive urine samples from catheterized patients (symptomatic and asymptomatic) admitted in various clinical wards of hospital were collected after obtaining informed consent.

Collection And Sample Processing: Samples collected in sterile containers with proper aseptic precautions were cultured on Mac Conkey agar and blood agar, incubated overnight aerobically at $37^{\circ} \mathrm{C}$. A specimen was considered positive, if a single / two potential pathogens were cultured at a concentration of $\geq 10^{3}$ Colony forming unit (CFU)/ $\mathrm{ml}$ from catheterized urine specimens $\mathrm{s}^{5}$. Organisms were identified by conventional microbiological methods ${ }^{5}$ and subjected to biofilm detection by following methods.

\section{Biofilm Detection Method}

1. Tissue Culture Plate Method (TCP) ${ }^{6}$ Organisms isolated from fresh agar plates were inoculated in Brain 
heart infusion broth (BHI) with $2 \%$ sucrose. Broth was incubated at $37^{\circ} \mathrm{C}$ for 18 hours. The broth culture was then diluted 1:100 with fresh medium. Individual wells of sterile 96 well flat bottom polystyrene tissue culture plates were filled with 200 ul of the diluted cultures. The wells were washed with phosphate buffer saline (ph7.2). Biofilm formed by bacteria adherent to the wells was fixed by $2 \%$ sodium acetate and stained by crystal violet $(0.1 \%)$. Excess stain was removed by using deionized water and plates will be kept for drying. Optical density (OD) of stained adherent bacteria was determined with an ELISA reader at wavelength of $570 \mathrm{~nm}$. These OD values were considered as an index of bacterial adherence and biofilm formation.

Table 1: Classification of bacterial adherence by TCP method.

\begin{tabular}{|l|l|l|}
\hline Mean OD & Adherence & Biofilm Formation \\
\hline$<0.120$ & Non & Non/weak \\
\hline $0.120-0.240$ & Moderate & Moderate \\
\hline$>0.240$ & Strong & High \\
\hline
\end{tabular}

2. Tube Method (TM) ${ }^{7}$ A qualitative assessment of biofilm formation was done using TM. A loopful of organisms from overnight culture plates were inoculated in $10 \mathrm{ml}$ of BHI with $2 \%$ sucrose in test tubes. The tubes were incubated at $37^{\circ} \mathrm{C}$ for 24 hours. After incubation, tubes were decanted and washed with crystal violet $(0.1 \%)$. Excess stain was washed with deionized water. Tubes dried in inverted position and observed for biofilm formation. Biofilm formation was considered positive when a visible film lined the wall and bottom of the tube. Tubes were examined and the amount of biofilm formation was scored as 0-absent, 1-weak, 2-moderate and 3-strong.

3. Congo Red Agar Method (CRA) -Freeman et $\mathrm{al}^{8}$ had described an alternative method for screening biofilm formation which requires the use of a specially prepared solid medium-Brain heart Infusion broth (BHI) supplemented with 5\% sucrose and Congo red. The medium was composed of BHI-37gm/1, sucrose$50 \mathrm{gm} / 1$, agar $10 \mathrm{gm} / 1$ and Congo red stain- $0.8 \mathrm{gm} / 1$. Congo red was prepared as concentrated aqueous solution and autoclaved at $121^{\circ} \mathrm{C}$ for $15 \mathrm{~min}$, separately from other medium constituents and then added when the agar had cooled to $55^{\circ} \mathrm{C}$. Plates were inoculated and incubated aerobically for 24 to 48 hours at $37^{\circ} \mathrm{C}$. Positive results were shown as black colonies with a dry crystalline consistency.

\section{Result}

Demographic characteristics of the study subjects showed that among 150 catheterized patients (age range 16-65 years) majority were males $112(74.66 \%)$ and 38(25.33\%) were females and there was no predilection of infection to any particular gender, patients of both genders were affected, males being marginally more than females.

Significant bacteriuria was observed among 113/150 $(75.33 \%)$ patients. Distribution of culture results is shown in figure 1.

Out of 113 isolates, $101(89.38 \%$ ) were gramnegativebacteria (GNB) and 12(10.61\%) were gram positive. Escherichia coli was most common isolate 30/101(29.70\%). Non E.coli Enterobacteriaceae (NECE) isolates include Klebsiella spp. 25/101(24.75\%), Citrobacter spp. 07/101(6.93\%), Proteus spp. 17/101(16.83\%) among non-fermenter bacteria Pseudomonas aeruginosa 21/101(20.79\%). Bacteriological profile of isolates is discussed in figure 2.

Isolates were screened for biofilm formation by TCP, TM and CRA methods. Results of phenotypic detection methods are shown in Table2.

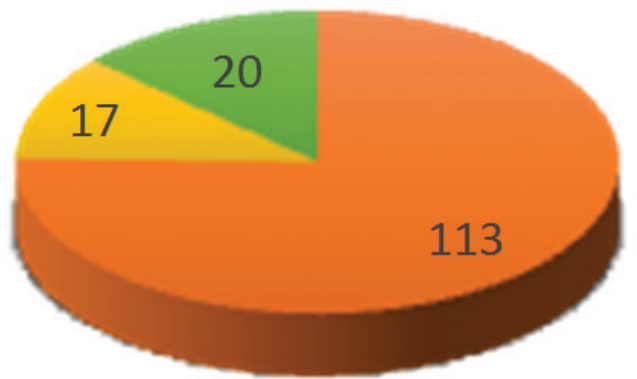

Significant Bacteriuria Mixed growth $\quad$ Sterile sample

Fig. 1: Distribution of culture results. 


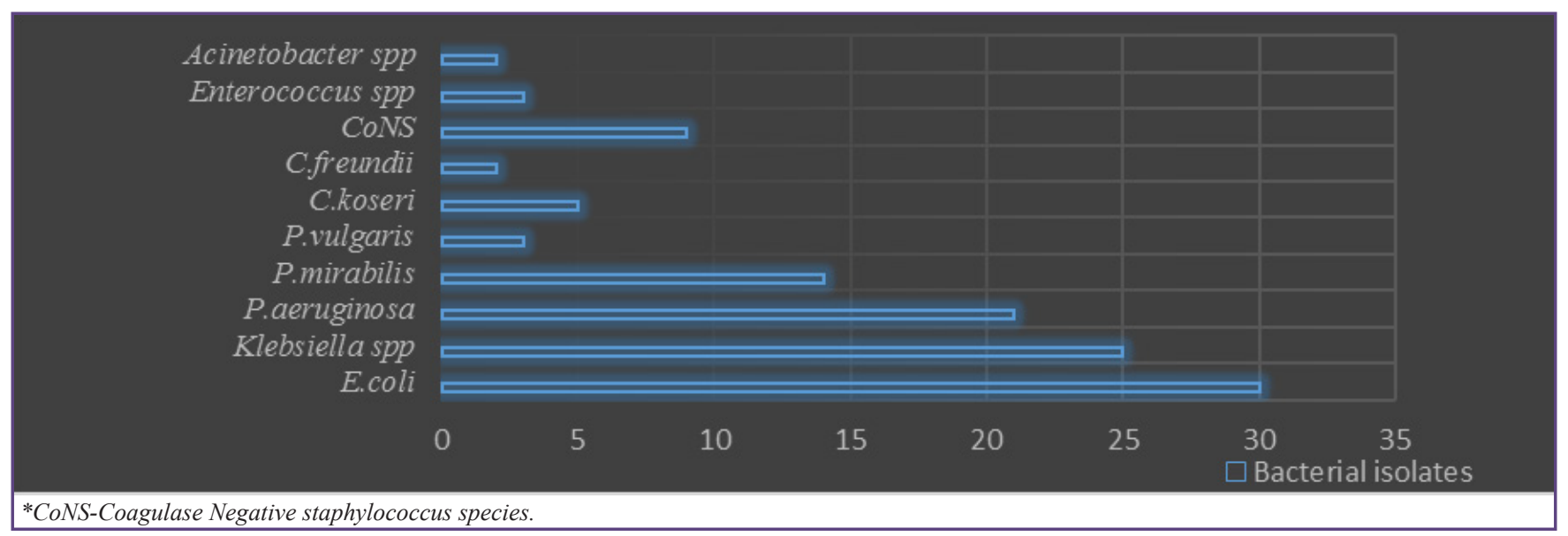

Fig. 2: Bacteriological Profile of Isolates.

Table 2: Biofilm detection by various methods.

\begin{tabular}{|c|c|c|c|c|c|c|}
\hline \multirow{3}{*}{ Bacterial Isolates } & \multicolumn{6}{|c|}{ Detection Methods } \\
\hline & \multicolumn{2}{|c|}{ Tissue culture plate Method } & \multicolumn{2}{|c|}{ Tube Method } & \multicolumn{2}{|c|}{ Congo red Agar Method } \\
\hline & (n) & $(\%)$ & (n) & $(\%)$ & (n) & $(\%)$ \\
\hline$n=113$ & 79 & 69.91 & 60 & 53.09 & 11 & 09.73 \\
\hline
\end{tabular}

Maximum biofilm producers were detected by TCP $79(69.91 \%)$ as compared to TM $60(53.09 \%)$ and CRA $11(9.73 \%)$ respectively. TM showed good correlation with the TCP assay for strong biofilm forming isolates and total 19 were picked up as strong and 41 as moderate and 53 as weak respectively. However, it was difficult to discriminate between moderate and weak biofilm producing isolates. By CRA method, most strains displayed pink to orange colonies. Only 11/113 (9.73\%) isolates displayed black colonies with or without dry crystalline morphology. No correlation between colony morphology on CRA and TCP results was observed. A result of biofilm formation by various methods is shown in Table 3 .

TCP method was considered the gold-standard for this study and compared with data from TM and CRA methods. Parameters like sensitivity, specificity, negative predictive value, positive predictive value and accuracy were calculated. True positives were biofilm producers by TCP, TM and CRA method. False positive were biofilm producers by TM and CRA method and not by TCP method. False negative were the isolates which were non-biofilm producers by TM and CRA but were producing biofilm by TCP method. True negatives are those which were non biofilm producers by all the three methods. Sensitivity and specificity of TM was $73.90 \%$ and $96.85 \%$ respectively. For CRA method, sensitivity and specificity remained low and were $11.24 \%$ and $98.43 \%$ respectively (Table 4 ).

\section{Discussion}

Urinary tract infection, its diverse clinical syndromes and affected host groups, remains one of the most common but widely misunderstood and challenging infectious diseases

Table 3: Detection of biofilm formation .

\begin{tabular}{|c|c|c|c|}
\hline Biofilm Formation & Tissue Culture Plate & Tube Method & Congo Red Agar \\
\hline High & 25 & 19 & 11 \\
\hline Moderate & 54 & 41 & - \\
\hline Weak/None & 34 & 53 & 102 \\
\hline
\end{tabular}

Table 4.Stastical analysis of biofilm formation by Tube method \& Congo red method.

\begin{tabular}{|c|c|c|c|c|c|}
\hline $\begin{array}{c}\text { Biofilm detection } \\
\text { Method }\end{array}$ & $\begin{array}{c}\text { Sensitivity } \\
(\%)\end{array}$ & $\begin{array}{c}\text { Specificity } \\
(\%)\end{array}$ & $\begin{array}{c}\text { Positive Predictive Value } \\
(\%)\end{array}$ & $\begin{array}{c}\text { Negative Predictive Value } \\
(\%)\end{array}$ & $\begin{array}{c}\text { Accuracy } \\
(\%)\end{array}$ \\
\hline TM & 73.90 & 96.85 & 97.87 & 65.43 & 81.65 \\
\hline CRA & 11.24 & 98.43 & 93.33 & 36.13 & 40.69 \\
\hline
\end{tabular}




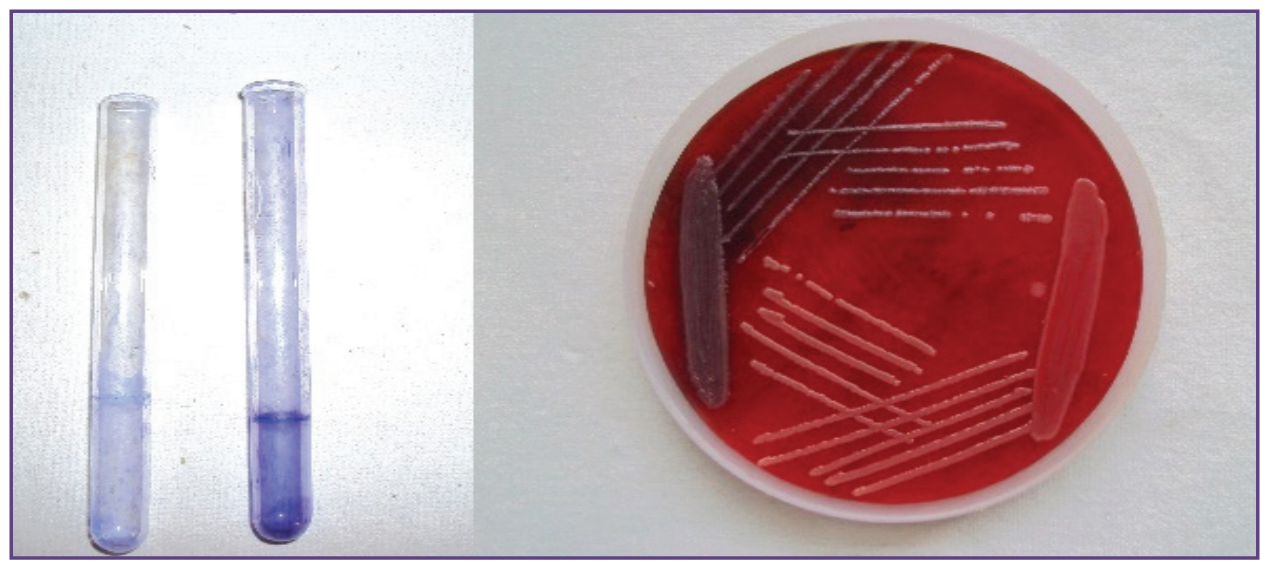

Fig. 3: Biofilm detection by Tube Method and Congo Red Agar Method.

encountered in clinical practice. Risk of developing urinary tract infection increases significantly with use of indwelling devices. ${ }^{[9]}$ Catheter in urinary tract disrupts normal host defenses, resulting in over distension of the bladder and incomplete voiding that leaves residual urine for microbial growth favoring bacterial colonization. Due to introduction of foreign body, pathogens require few recognized virulence factors to colonize and establish infection than to infect fully functional urinary tract. ${ }^{10}$ Biofilm mode of growth has been well documented as one of the important cause of prosthetic device related infections that are refractory of treatment. ${ }^{[1]}$

In present study significant bacteriuria was observed as $75.33 \%$ (occurrence of high incidence of single infection in our study may be explained by the heavy use of broad spectrum antibiotics). This is in concordance with Bakke et $\mathrm{a}^{\left[{ }^{12]}\right.}$ who observed $50.6 \%$ significant bacteriuria among catheterized patients. However, Teshager L and colleagues ${ }^{[13]}$ observed $43.30 \%$ significant bacteriuria among catheterized. This suggested, over time urinary catheters become colonized with microorganisms living in sessile state within the biofilm, rendering them resistant to antimicrobial and host defenses and virtually impossible to eradicate without removing the catheter ${ }^{[14]}$ Not only does the urinary catheter invite biofilm formation, but presence of catheter itself impairs many normal defense mechanisms. Also, urinary catheter connects heavily colonized perineum with the normally sterile bladder, and it provides a route for bacterial entry along both its external and internal surfaces. ${ }^{[15]}$

GNB were predominant isolates 101(89.38\%) and Escherichia coli was most common isolate 30/101(29.70\%).Other isolates include Klebsiella spp. 25/101(24.75\%), Citrobacter spp. 07/101(6.93\%), Proteus spp. 17/101(16.83\%) and Pseudomonas aeruginosa 21/101(20.79\%). Gram positive (GPB) constitute
$12 / 113(10.61 \%)$. This is in accordance with Hassan et a ${ }^{16}$ and Niveditha $\mathrm{S}$ et al ${ }^{[17]}$ who also observed E.coli as most common uropathogen among catheterized patients.

In current study, biofilm production was seen in $69.91 \%$ of uropathogens. Though many studies ${ }^{[17,18]}$ have shown variable biofilm formation $(45 \%-60 \%)$ among uropathogens. With respect to phenotypic biofilm detection methods we screened isolates by $\mathrm{TCP}^{[6]}, \mathrm{TM}^{[7]}$ and $\mathrm{CRA}^{[8]}$ methods because of their ease of performance in routine laboratory settings for determining biofilm formation. TCP method detected 79/113(69.91\%) as biofilm producers. Out of which, 25 were high, 54 were moderate and 34 were non biofilm producers.

Tube method detected 60/113 (53.09\%) as biofilm producers. Among them, 19 were strong and 41 were moderate and 53 were non biofilm producers. With CRA method most strains displayed red (pink to orange) colonies and only $11(9.73 \%)$ showed black colonies with dry crystalline morphology (Table 3 ). Our results are in agreement with other investigators as shown in table 5.

Considering TCP as gold standard in this study parameters like sensitivity, specificity, NPV, PPV and accuracy were calculated. Our data indicates that TM is $73.90 \%$ sensitive, $96.85 \%$ specific and $81.65 \%$ accurate method. Based on our observations we don't recommend CRA method as suitable method for biofilm screening. (Table 4). Our results are in agreement with other investigators as shown in table 6 .

Other studies ${ }^{[23,24]}$ comparing TM with gold standard TCP demonstrated sensitivity varies from $61 \%$ to $100 \%$ and specificity $66 \%$ to $100 \%$.

But due to subjective variations in interpretation and lack of reproducibility among test results TM cannot be suggested as general screening test to identify biofilm 
Table 5: Biofilm formation observed by TCP, TM and CRA in other studies.

\begin{tabular}{|c|c|c|c|c|}
\hline \multirow{2}{*}{ Year } & \multirow{2}{*}{ Author } & \multicolumn{3}{|c|}{ Biofilm detection method } \\
\cline { 2 - 4 } & Turkyilmaz et al (19) & TCP & TM & $61.10 \%$ \\
\hline 2006 & Hassan et al (20) & $50.50 \%$ & $55.55 \%$ & $11 \%$ \\
\hline 2011 & Nabajit Deka (21) & $83.63 \%$ & $54 \%$ & $20 \%$ \\
\hline 2014 & Mohamad E et al (18) & $45.6 \%$ & $38.11 \%$ & $36.9 \%$ \\
\hline 2015 & Tayal R et al (22) & $27 \%$ & $37.96 \%$ & $40.88 \%$ \\
\hline 2015 & & & & \\
\hline
\end{tabular}

Table 6: Sensitivity and specificity as observed by other authors.

\begin{tabular}{|c|c|c|c|c|}
\hline \multirow{2}{*}{ Year \& Author } & \multicolumn{2}{|c|}{ TM } & \multicolumn{2}{c|}{ CRA } \\
\cline { 2 - 5 } & Sensitivity & Specificity & Sensitivity & Specificity \\
\hline 2011, Hassan A et al (20) & $73.00 \%$ & $92.50 \%$ & $11.00 \%$ & $92.00 \%$ \\
\hline 2015, Tayal R et al (22) & $94.59 \%$ & $83.00 \%$ & $94.59 \%$ & $81.00 \%$ \\
\hline Present study & $73.90 \%$ & $96.85 \%$ & $11.24 \%$ & $98.43 \%$ \\
\hline
\end{tabular}

producing isolates. Thus, we conclude from our study that TCP is a quantitative and reliable method to detect biofilm forming microorganisms. When compared to TM and CRA methods, TCP can be recommended as a general screening method for detection of biofilm producing bacteria in laboratories.

\section{Conclusion}

Unique and changing properties of biofilm-positive microbes made them responsible for recalcitrant infection, which are difficult to eradicate. The presence of biofilm is probably underestimated because of lack of in vitro diagnostics. Thus, dynamic research activity is required in this field as this bacterial lifestyle may be associated with human infectious diseases.

\section{Reference}

1. Donlan RM. Biofilms; Microbial life on surface. Emerg Infect Dis. 2002;8(9):881-90. PMID:12194761.

2. Mah TF, O'Toole GA.Mechanism of Biofilm resistance to antimicrobial agents. Trends Microbiol. 2001 ;9(1);34-39. [PMID:11166241].

3. Costerton JW, Lewandowski Z, Caldwell DE, Korber DR, Lappin Scott HM. Microbial biofilms. Annu Rev Microbiol. 1995;49:711-45.

4. Bordi and de Bentzmann: Hacking into bacterial biofilms: a new therapeutic challenge. Annals of Intensive Care. 2011 1:19. (doi:10.1186/2110-5820-1-19)

5. Collee JG, Duguid JP, Fraser AG, Marmion B P, Simmons A. Laboratory strategy in the diagnosis of infective syndrome. In Collee JG, Fraser AG, Marmion BP, Simmons A, editors. Mackie \& McCartney Practical Medical Microbiology. 14thed. New Delhi: Elsevier, a division of Reed Elsevier India Pvt. Ltd. 2006. P. 53-94.
6. Christensen GD, Simpson WA, Younger JA, Baddour LM, Barrett FF, Melton DM et al. Adherence of Coagulase negative Staphylococci to plastic tissue cultures: a quantitative model for the adherence of Staphylococci to medical devices. J. Clin.Microbiol.1985;22:996-1006. [PMID: 3905855 PMCID:PMC271866].

7. Christensen GD, Simpson Wa, Bisno AL, Beachey EH. Adherence of slime producing strains of Staphylococcus epidermidis to smooth surfaces. Infect. Immunol.1982 ;37(1):318-26. [PMID:6179880].

8. Freeman DJ, Falkiner FR, Keane CT. New method for detecting slime production by coagulase negative staphylococci. J Clin Pathol.1989 ;42(8):872-4. [PMID:2475530].

9. Abdallah NMA, Elsayed SB, Mostafa MY, Elgohary GM. Biofilm forming bacteria isolated from urinary tract infection, relation to catheterization and susceptibility to antibiotics. Int J Biotech and mol bio research.2011;2(10):172-8.

10. Jain P, Parada JP, David A, Smith LG. Overuse of the indwelling urinary tract catheter in hospitalized medical patients. Arch. Intern. Med. 1995 :155 (13);1425-9. [PMID:7794092].

11. Yassien M, Khardori N. Interaction between biofilms formed by Staphylococcus epidermidis and quinolones. Diag Microbiol Infect Dis.2001;40:79-89. [PMID:11502373].

12. Bakke A, Digranes A. Bacteriuria in patients treated with clean intermittent catheterization. Scand J Infect Dis. 1991;23(5):577-82. [PMID:19865057].

13. Teshager L, Asrat D, Tamiru S. Catheterized and noncatheterized urinary tract infections among patients attended at Jimma University Teaching Hospital, Southwest, Ethiopia. Ethiop Med J. 2008 Jan;46(1):55-62. [PMID:18711990].

14. Nickel JC, Costerton JW, McLean RJ, Olson M. Bacterial biofilms: influence on the pathogenesis, diagnosis and treatment of Urinary tract infections. J Antimicrob Chemother 1994;33 Suppl A:31-41.[PMID:7928835]. 
15. Lee JH, Kim SW, Byung Y, Wan D, Cho WH. Factors That Affect Nosocomial Catheter-Associated Urinary Tract Infection in Intensive Care Units: 2-Year Experience at a Single Center. Korean J Urol. 2013;54:59-65. [doi:10.4111/kju.2013.54.1.59]

16. Hassan SKR. Studies on urinary tract infections in Bangladesh. Med J. 1991;20:29-32.

17. Niveditha S, Pramodhini S, Umadevi S, Kumar S, Stephen $\mathrm{S}$. The isolation \& the biofilm of uropathogens in the patients with CA-UTI. J Clin Diag Res. 2012 ;6(9):1478-83. [doi: 10.7860/JCDR/2012/4367.2537].

18. Mohamed E, Shalakany HE. Detection of biofilm formation in uropathogenic bacteria. Egypt $\mathrm{J}$ Med Microbiol.2015;24(1):49-57.

19. Turkyilmaz S, Ezkiizmirliler S. Detection of Slime factor production and antibiotic resistance in Staphylococcus strains isolated from various animal clinical samples. Turk J Vet Anim Sci. 2006;30:201-6.

20. Hassan A, Usman J, Kaleem F, Omalr M, Khalid A, Iqbal M.Evaluation of different detection methods of biofilm formation in clinical isolates. Braz $\mathrm{J}$ Infect Dis.2015;15(4):305-11. [PMID:21860999]

21. Nabajit D. Comparison of tissue culture plate, tube method and Congo Red Agar method for the detection of biofilm formation by coagulase negative Staphyloccus isolated from non clinical samples. Int $\mathrm{J}$ Curr Microbiol App Sci.2014;3(10):810-5.

22. Tayal R, Baveja S, De Anuradha. Comparison of phenotypic methods for detection of Biofilm production in uropathogens in tertiary care hospital in India. Int J Curr Microbiol App Sci.2015;4(9):840-9.

23. Pahraj I, Sistla S, Parija SC. Virulence factors in clinical and commensal isolates of Enterococcus species. Ind J Path Microbiol. 2013;56(1):24-30. [doi: 10.4103/03774929.116144] [PMID:23924554]

24. Golia S, Hittinahalli V, Karjigi S K, Reddy K M. Correlation between biofilm formation of uropathogenic Escherichia coli and its antibiotic resistance pattern. J Evol Med Den Sci.2012;1(3):166-75.

*Corresponding author:

Dr. Pallavi Sayal, 154-New Hardev Nagar, Kapurthala road, Jalandhar city,Punjab.PIN-144002. INDIA

Phone: +91 9779906099

Email: petalz03@gmail.com

Date of Submission : 05.09.2016

Date of Acceptance : 22.11.2016

Financial or other Competing Interests: None.

Date of Publication : 19.02.2017 